\title{
Verzeichnis des abgekürzt zitierten Schrifttums
}

Siehe das entsprechende Verzeichnis bei den Erläuterungen zu Art 18, 19 a F EGBGB. Nachfolgend einige Ergänzungen:

BöHMER-SIEHR . . . . . . . Das gesamte Familienrecht, Bd 2: Das internationale Recht (3. Aufl $1979 \mathrm{ff}$ ).

FERID, IPR . . . . . . . . . Internationales Privatrecht. Das neue Recht. Ein Leitfaden für Praxis und Ausbildung (3. Aufl 1986).

HdbIZVR . . . . . . . Handbuch des Internationalen Zivilverfahrensrechts, Bd I (1982), Bd III/1 und III/2 (1984).

KegEL . . . . . . . . . . . Internationales Privatrecht (6. Aufl. 1987).

KeIDEL-Kuntze-WinkLer . . . . . Freiwillige Gerichtsbarkeit, Teil A (12. Aufl 1987).

Palandt-Heldrich . . . . . . . Bürgerliches Gesetzbuch (46. Aufl 1987).

SOERGRL-KeGEL . . . . . . . . Bürgerliches Gesetzbuch, Bd 8 (11. Aufl 1983). 
